This is a pre-publication version of this paper. The definitive version is available from:

http://onlinelibrary.wiley.com/doi/10.1111/hojo.12034/abstract

\title{
‘SWIFT, SIMPLE, EFFECTIVE JUSTICE?’ IDENTIFYING THE AIMS OF PENALTY \\ NOTICES FOR DISORDER AND WHETHER THESE HAVE BEEN REALISED IN \\ PRACTICE
}

\begin{abstract}
Since the introduction of penalty notices for disorder (PNDs), there has been no clear political statement as to the purpose of the scheme. The findings of a grounded analysis of the relevant parliamentary debates, consultation papers and White Papers on PNDs (which have not received any consideration in the literature thus far) are presented, providing an overall thematic framework within which to understand and assess PNDs. The findings of a critical review of 250 PNDs undertaken by the author are considered in light of this framework, to ask whether, and to what extent, PNDs achieve their aims.
\end{abstract}

Key Words: Penalty Notices for Disorder, Police, Summary Justice

\section{Introduction}

Introduced under the Criminal Justice and Police Act 2001, Penalty Notices for Disorder (PNDs) are 'on-the-spot' fines which may be issued by police officers (and for many offences by), police community support officers (PCSOs) and other accredited persons. A PND is not a conviction; it requires no admission of guilt from the recipient and they do not receive a criminal record (although, if deemed relevant to the post applied for, PNDs may appear on an enhanced criminal records check)i. Instead, payment of a PND discharges the recipient's liability to be proceeded against in the courts. Whilst often referred to as 'on-the-spot fines', PNDs may be issued either on the street or at the police station following arrest. There are two levels of 'penalty offence' (offences which may be disposed of via PND); lower tier offences incur a $£ 50$ fee, higher tier offences, $£ 80$. PND recipients have 21 days to pay the notice or request a court hearing after which it will be registered as a fine (for one and half times the original amount) at the magistrates' court ${ }^{\mathrm{ii}}$. 
This is a pre-publication version of this paper. The definitive version is available from: http://onlinelibrary.wiley.com/doi/10.1111/hojo.12034/abstract

Penalty Notices for Disorder should be distinguished from Fixed Penalty Notices (FPNs). Whilst FPNs have existed in England and Wales since the 1950s (Fox 1995), PNDs were rolled-out in 2004 and unlike their counterparts, which are focused on traffic, environmental and other regulatory offences, PNDs reach "firmly into the mainstream of criminal behaviour" (Young 2008, p.169). Since its introduction the remit of the PND scheme has been hugely extended; initially focussed on minor incidents of adult disorder (focusing on 'false alarm' cases and alcohol-related nuisance), subsequent amendments have seen the number of penalty offences rise from 10 to 26 with additions including s5 of the Public Order Act 1986 (behaviour likely to cause harassment alarm or distress, s5 hereafter), theft, criminal damage and possession of cannabis. In 2010 140,769 PNDs were issued in England and Wales; far greater numbers of people received PNDs for drunk and disorderly behaviour and s5 than were proceeded against at the magistrates' court ${ }^{\mathrm{iii}}$. PNDs are now part of the mainstay of the criminal justice system and yet little is known about how these notices are used in practice.

According to the Home Office (2012a) PNDs offer swift, simple and effective justice, their use deter offenders, reduces the burden on both the police and courts, and increases the time officers spend on the beat and dealing with serious offending. This is quite a list of achievements for one of many anti-social behaviour powers. But do PNDs achieve these aims? The PND scheme has been characterised by a lack of consultation, a failure to fully evaluate the impact of PNDs on recipients or the courts and a complete lack of consideration as to the legitimacy of empowering the police (or PCSOs and other accredited persons) to issue punishments. The key contribution of this paper will be to begin addressing these serious shortcomings and open the debate on PNDs for further research.

Whether PNDs can be deemed to be achieving their aims depends upon the parameters set for 'achievement'. This paper presents the findings of an extensive grounded analysis 
This is a pre-publication version of this paper. The definitive version is available from: http://onlinelibrary.wiley.com/doi/10.1111/hojo.12034/abstract

(Silverman 2010) of the relevant parliamentary debates, consultation papers and White Papers ${ }^{\mathrm{iv}}$ on PNDs. This provides a thematic framework within which to understand and assess PNDs. The paper firstly considers the aims of the PND scheme (as outlined in those documents) which were categorised by the author as: managerialist, reductionist, punishment and rehabilitation ${ }^{v}$. The concerns regarding PNDs, which related to police discretion and subjectivity, human rights and due process, and equality of impact, are then examined. The basis of each of these arguments is set out and reflected upon in turn, before presenting an initial assessment as to whether (and to what extent) that aim/concern has been realised in practice. This assessment is based on the findings of a critical review of 250 penalty notice tickets undertaken by the author $^{\text {vi }}$, as well as the PND pilot study (Halligan-Davis and Spicer 2004; Spicer and Kilsby 2004), two Office for Criminal Justice Reform reviews on the use of PNDs (Office for Criminal Justice Reform 2011; Kraina and Carroll 2006) and the national data on their use (Ministry of Justice 2011). The discussion on each theme is followed by a brief conclusion. The paper concludes by considering if, and how, PNDs fit within the broader anti-social behaviour (ASB) and crime policy, examining how more recent developments in the PND scheme initiated by the current government essentially continue the themes laid out under Labour.

\section{Policy Aims of Penalty Notices for Disorder}

The overarching aim stated in the consultation paper when introducing PNDs was to more effectively tackle the disorderly behaviour which undermines individuals' and communities' quality of life; and, through the use of PNDs, treat such behaviour "seriously"; four specific aims were outlined (Home Office 2000, p.1) (italics added): 
This is a pre-publication version of this paper. The definitive version is available from: http://onlinelibrary.wiley.com/doi/10.1111/hojo.12034/abstract

1. To enable the police to put an immediate stop to misbehaviour

2. To provide a swift punishment

3. To provide a 'real practical deterrent' which '[takes] up as little police time as possible"

4. To reduce police time spent on paperwork and court appearances

Whilst the government therefore sought PNDs to stop disorderly behaviour, punish offenders and reduce crime, the consistent aim within all of the above was that of saving police time. Yet despite this PNDs were to be available both for offences which would (prior to their introduction) attract a court fine and, behaviour which might previously have attracted an informal warning. This highlights confusion in their purpose from the outset: PNDs would supposedly simultaneously divert cases from court and punish cases that would not previously have reached the courts. It was unclear therefore whether the government were upgrading their response to disorder or downgrading the response to crime (although the inclusion of offences such as theft and criminal damage suggests the latter). When considering whether the PND scheme achieves its aims we must therefore recognise that these aims are quite ambiguous and at times appear contradictory.

\section{Managerialist}

Managerialist arguments, that PNDs would save police time (Home Office 2000), dominated the political debate on penalty notices. Managerialist support centred upon the notion that PNDs would "speed up the whole process of bringing offenders to justice and to save bureaucracy" (Lord Cope (Con), HL Deb (2000-1) 624 col. 661). Concerns were raised that PNDs dilute "[t]he principles and the protections of the criminal law, in particular the presumption of 
This is a pre-publication version of this paper. The definitive version is available from: http://onlinelibrary.wiley.com/doi/10.1111/hojo.12034/abstract

innocence and the burden of proof" (Lord Windlesham (Con) HL Deb (2000-1) 624 col. 676). PNDs were thought to blur criminal and civil procedures and threaten due process. The potential benefits of reduced bureaucracy however ultimately defeated these human rights concerns. Indeed Lord Renton argued "I, too, have doubts about the whole principle of on-the-spot fines. However, we must realise that the proposal will save public money because it will save the time of the courts" (Lord Renton (Con), HL Deb (2000-1) 625 col.482). But, if they are used to punish offenders who previously avoided formal punishment, can they save time? I would argue that the realisation of these managerialist aims is dependent on a number of factors; firstly, that the time and cost associated with issuing a PND compares favourably to other disposals; secondly, that PNDs are issued on the spot; thirdly, that PNDs are used to divert cases from court rather than bring cases into the criminal justice system; and finally, that PNDs are paid promptly.

Do these factors occur? Some efficiency savings do appear to have been realised in practice; PNDs take approximately 30 minutes of police time compared to the 6.5 hours taken to gather evidence and prepare for an average arrest, (Home Office 2006, quoted in Centre for Social Justice 2009). However, whilst street-issued PNDs cost between $£ 5$ and $£ 40$ this rises to between $£ 250$ and $£ 350$ for notices issued in custody (OCJR 2011). Potential savings are thus undermined given that in 2010 50\% of all PNDs were issued in custody (Ministry of Justice 2013). Furthermore, whilst the cost of issuing a PND compares favourably to issuing a caution or pursing a prosecution (£300-£450 and £400-£1400 respectively) (OCJR 2011), it is questionable whether such comparisons are fair given that PND cases may not have previously resulted in any formal action. Indeed, the PND pilot study found that between half and three-quarters of all s5 and drunk and disorderly notices were "new business' (Halligan-Davis and Spicer, 2004); this was further supported by the recent OCJR (2011) review of out of court disposals. 
This is a pre-publication version of this paper. The definitive version is available from: http://onlinelibrary.wiley.com/doi/10.1111/hojo.12034/abstract

Thus rather than reducing police paperwork, PNDs have created more opportunities for formal punishment (with all the associated administration for both the police and the courts). Potential efficiency savings are further undermined by poor compliance with PNDs; in 2010 $37 \%$ of PNDs were registered as a court fine (Ministry of Justice 2011, Table A2.1), meaning over 50,000 tickets fell to the courts to be enforced. Thus despite the government rhetoric, any savings offered by PNDs are questionable given the net-widening associated with PND cases, the high proportion of tickets issued in custody and the low payment rate.

\section{Reductionist}

Two reductionist arguments emerged from the political debates and policy on PNDs. Firstly, that PNDs would provide a deterrent both to individual recipients, who would seek to avoid further fines, and to the general public who, seeing PNDs being issued, would be deterred by the knowledge that police will punish disorderly behaviour. The view that PNDs would act as a deterrent to minor offences was supported by both Houses, "showing that the law will bite without delay if people are intent upon disorderly and anti-social behaviour" (Baroness Buscombe (Con), HL Deb (2000-1) 625 col.503). Any deterrent effect was however recognised to be associated with the means of the recipient; the well off were thought to be less likely to be deterred or view the fine as a punishment at all (Simon Hughes (Lib Dem), Stg Co Deb (20001) Co F Criminal Justice and Police Bill, no pagination). The second reductionist argument was that the associated savings in police time (through reduced paperwork and court appearances) would aid crime reduction, PNDs would provide a quicker means of dealing with low-level offending and therefore "free [officers] to spend more time on the streets, deterring crime and dealing with other [more serious] offenders" (Hazel Blears (Lab), Stg Co Deb (2003-4) Fourth Delegated Legislation Committee, $14^{\text {th }}$ September 2004, col.003). The overarching managerialist justifications for the use of PNDs are apparent in this reductionist aim. However this argument moves beyond the suggestion that PNDs would improve efficiency to consider 
This is a pre-publication version of this paper. The definitive version is available from: http://onlinelibrary.wiley.com/doi/10.1111/hojo.12034/abstract

how those time savings may be used. Thus through the use of PNDs, the police may focus on, and reduce, not only those low-level offences to which PNDs apply but more serious offences.

The notion that PNDs allow officers to spend more time on the streets is however undermined by both the net-widening associated with the PND scheme and the high proportion of notices issued in custody (Halligan-Davis and Spicer 2004, Ministry of Justice 2013). Furthermore, any general deterrent effect seems questionable; it relies upon the assumption that people are aware of this power and will see notices being issued. However this limits any deterrent value of PNDs to street issued notices and assumes that members of the public would be in the vicinity of a PND recipient throughout the (15-30 minute) issuing process. Whilst arguably public awareness could be raised through media and political focus on PNDs, this too has been lacking. With the exception of the occasional article on celebrity recipients, PNDs are rarely mentioned in the media, with reporting on PNDs being greatly over-shadowed by that on ASBOs. Indeed since 2001 there have been 892 mentions of PNDs across all the major national and local newspapers in the UK, compared to 18,580 references to anti-social behaviour $\operatorname{orders}^{\text {vii }}$.

There is some indication that PNDs are achieving their individual deterrent aim: reoffending rates were lower for PND recipients (25\%) than for people who were released from custody or commenced a court order (39\%). However PND recipients were more likely to reoffend than those who had been cautioned (18\%) (OCJR 2011) viii. Furthermore, those figures do not include receipt of a subsequent PND, yet during the year-long pilot study $8 \%$ of PNDs were issued to persons who had already received at least one notice (Halligan Davis and Spice 2004) and it is likely that over a longer follow-up period there may be a greater proportion of repeat 'PND offenders'. Thus whilst the government sought PNDs as a deterrent to offending, in placing no statutory limit on the number which may be issued (with the exception of theft cases), any deterrent purpose (or effect) is undermined. 
This is a pre-publication version of this paper. The definitive version is available from: http://onlinelibrary.wiley.com/doi/10.1111/hojo.12034/abstract

\section{Punishment}

Throughout their brief history PNDs have been promoted as a means of providing a swift punishment for 'low-level' and first-time offending, which recognises that such behaviour is wrong, whilst not criminalising a "one-off piece of foolishness" (Baroness Scotland of Asthal (Lab), HL Deb (2003-4) 664 col.988). Labour argued that PNDs ensure that behaviour which (due to resource constraints on the police) may otherwise fall through the net, does not avoid punishment (Hazel Blears (Lab), Stg Co Deb (2003-4) Second Delegated Legislation Committee, $8^{\text {th }}$ September 2004, col.005). The potential net-widening impacts of PNDs discussed above were therefore not only recognised but endorsed. Whilst all political parties supported the PND scheme in principle, disputes arose as to the seriousness of offences to which it should apply; indeed, the government were accused of "dumbing down...justice with the inclusion of offences that should be prosecuted" (David Burrowes (Con), Stg Co Deb (20089) Third Delegated Legislation Committee, $22^{\text {nd }}$ January 2009, col.6). Despite such concerns, since the scheme's inception the number of penalty offences has more than doubled and there has been a shift in emphasis from disorder to crime. Yet despite this (or perhaps because of this), PNDs continue to be described as a 'punishment' and have moved from being presented as an administrative to a criminal sanction (Hazel Blears (Lab) Stg Co Deb (2003-4) Second Delegated Legislation Committee, $8^{\text {th }}$ September 2004, col. 014; Maria Eagle (Lab), Stg Co Deb (2008-9) Third Delegated Legislation Committee, $22^{\text {nd }}$ January 2009, col.3).

At a time when there was (and is) growing concern with anti-social behaviour, PNDs offer a cost and time-efficient means of punishing offenders, however issuing a PND does not stop the individual from 'avoiding punishment'. For PND recipients to be deemed to have been 'punished' requires high levels of compliance and enforcement for non-payment. In practice however payment rates are relatively low, peaking at 55\% in 2010 (Ministry of Justice 2011, Table A2.1). The extent of enforcement for unpaid PNDs is unknown as court data make no distinction between these and court-issued fines. The pilot project however found that ultimately 
This is a pre-publication version of this paper. The definitive version is available from: http://onlinelibrary.wiley.com/doi/10.1111/hojo.12034/abstract

there was an overall payment rate of $70 \%$ (including those paid within 21 days of issue and those enforced by the courts). This suggests that up to $30 \%$ of people do not have their notice enforced and are not therefore 'punished' as the system dictates (Halligan Davis and Spicer 2004).

\section{Rehabilitation}

Whilst the Labour vision of PNDs was focused on efficiency and punishment, the Coalition Government have sought to add a rehabilitative element to PNDs; the Legal Aid, Sentencing and Punishment of Offenders Act 2011 (LASPO) enables Chief Constables to set up educational programmes which "reduce the likelihood of those who take the course committing the penalty offence[s]...to which the course relates" (LASPO Schedule 14) ${ }^{\text {ix }}$. PND recipients would have the option of attending such a course as an alternative to paying the penalty notice fee. The PND would be waived upon completion of the course. As the decision to establish such programmes is discretionary it will not be available for all PND recipients and, even where it is available, the content and duration of sessions may vary. Furthermore, the recipient must 'opt-in' to the scheme and thus to 'opt-in' to rehabilitation.

Rather than addressing these issues, the brief debate on this proposal was dominated by managerialist concerns as to whether, in a climate of public spending cuts, the police have the resources to establish such schemes. Such concerns were dismissed as Chief Constables would only establish such schemes if they would cover their costs. However, it is difficult to see how they can break even given that the course fee is to be less than the maximum $£ 80$ PND fine; issuing a PND costs anywhere between $£ 5$ and $£ 350$ (OCJR 2011) and the educational programmes piloted for the Alcohol Arrest Referral schemes cost between $£ 62$ to $£ 826$ per intervention (Blakeborough and Richardson 2012). Whilst any costs may, in theory, later be recouped through crime reduction, given that the Home Office (Blakeborough and Richardson 
This is a pre-publication version of this paper. The definitive version is available from: http://onlinelibrary.wiley.com/doi/10.1111/hojo.12034/abstract

2012) evaluation of Alcohol Arrest Referral schemes found that brief alcohol interventions did not reduce re-arrest rates it seems unlikely that PND education courses will achieve their aim.

\section{Concerns Raised with Regards to PNDs}

Although in principle the PND scheme was supported by all political parties, its introduction and extension have not been entirely uncontroversial, particular concerns were raised regarding: police discretion and subjectivity, human rights and equality of impact. The following section considers these arguments however, it should be noted that these concerns have not had any overt impact on the development of the PND scheme.

\section{Police Discretion and Subjectivity}

PNDs allow the police officer at the scene (who may well be the victim of the offence) to act as the 'judge and jury'. In parliament concerns were raised that PNDs would allow similar behaviour to be disposed of differentially and that PNDs may be issued, or be deemed to be issued, on prejudicial grounds. It was argued that such a system is open to abuse, police could target people they did not like and "pick on those who are already socially maladept or socially vulnerable" (Lord Bassam (Lab), HL Deb (2000-1) 625 col. 477). Such issues are not unique to PNDs. Indeed, these concerns are borne out in the policing literature which suggests that the police can, and do, use their discretion to target 'police property' (Lee, 1981 as cited in Reiner, 2010), using arrest to control the 'dross' in society (Choongh, 1998). PNDs have the potential to exacerbate this process; offering officers a means to dispense financial punishments alongside 'police justice'. The government dismissed such concerns stating that there was no evidence that the police would use their powers in a discriminatory fashion (ignoring evidence with regards to, for example, disproportionate use of stop and search powers against ethnic minorities (Equality and Human Rights Commission 2010)).

Particular concerns were raised with regards to the inclusion of s5, due to the subjective nature of the offence; age, location and time of day were cited as factors affecting whether 
This is a pre-publication version of this paper. The definitive version is available from: http://onlinelibrary.wiley.com/doi/10.1111/hojo.12034/abstract

behaviour might be deemed 'offensive' with Simon Hughes commenting that anyone on Old Kent Road at 2a.m. "knows the score...[and] would not be there if they expected a quiet journey home" (Stg Co Deb, (2000-1) Co F Criminal Justice and Police Bill, no pagination). Following its initial removal from the Criminal Justice and Police Bill 2001, s5 was reintroduced through secondary legislation in 2002. Despite voicing ongoing concerns the opposition in both Houses were swayed by the fact that ACPO supported the inclusion of s5; the police view s5 as operationally similar to drunk and disorderly and therefore believed the exclusion of s5 would undermine the scheme. However, is this a justifiable reason to increase police powers? As Simon Hughes (Lib) argued (with regards to PNDs in general) the support of ACPO is not objective "the police obviously want more powers" this is not a reason to give it to them (Stg Co Deb, (2000-1) Co F Criminal Justice and Police Bill, no pagination).

An examination of the use of s5 and drunk and disorderly PNDs in practice highlights the subjectivity of these offences. The current study found that the initial victim in these cases was commonly a police officer $(27 \%)$ or a person known to/fighting $(26 \%)$ with the PND recipient ${ }^{\mathrm{x}}$. The police were noted as at least one of the victims in $60 \%$ of these cases; however they were significantly more likely to be a victim in drunk and disorderly cases than in s 5 cases $(\mathrm{X} \square=5.893$, d.f $=2, \mathrm{p}=0.020$ ). Concerns regarding the subjectivity involved in $\mathrm{s} 5$ cases, and particularly concerns regarding officers' ability to sanction people for swearing at them appear therefore to have been realised to some extent in practice, and extend to drunk and disorderly cases. Whilst these cases occurred in a broader context of offending where abuse was directed at both the public and the police, these findings highlight the need for further research into the context in which PNDs are used and whether a police-issued fine is an appropriate means of dealing with such offences.

\section{Human Rights and Due Process}

A number of human rights concerns were raised with regard to the impact of PNDs: 
"[PNDs] reduce the burden of proof, remove the safeguards of the court process and impose penalties on an individual who is thought to be committing or to have committed those offences simply on a constable's belief. That is a dangerous principle to bring into the criminal law of this country." (Lord Thomas of Gresford (Lib Dem), HL Deb (2000-1) 625, col.482).

These concerns can be broadly subcategorised as concerns regarding the burden of proof and the right to trial.

\section{The Burden of Proof}

The burden of proof is a "golden thread in our criminal jurisprudence" (Lord Windlesham (Con) HL Deb (2000-1) 625, col.496) and must therefore be maintained when new, and untested, forms of penal sanction are introduced. Despite this (then Prime Minister) Tony Blair, proudly proclaimed that PNDs "[b]luntly reverse the burden of proof" (Blair 2006). This relates to both the legal and evidential burden; it is for the recipient to request a hearing and provide evidence of their innocence. In all but the $1 \%$ of cases each year where the PND recipient contests their notice, the issuing police officer is the trier of fact and therefore need only discharge the burden of proof to themselves. Furthermore, to issue a PND the officer need only have 'reason to believe' that a penalty offence had occurred, which is itself a subjective test. Arguably therefore, PNDs do not so much reverse as remove the burden of proof. The opposition proposed to amend the Bill so that officers must have (the more objective) 'reasonable grounds to believe' an offence had occurred, however the government rejected this saying that as a PND is not a criminal conviction and requires no admission of guilt, this lower standard was appropriate. Indeed, Lord Bassam (Lab) argued that were the criminal standard of proof to be applied it might be considered that PNDs were being used for more serious offences (HL Deb (2000-1) 625 col.499). This is questionable however as penalty offences are criminal offences; it remains open to the police to arrest and charge the perpetrators, or for recipients to request a court hearing, after which the higher standard of proof would be applied.

\section{The Right to Trial}


This is a pre-publication version of this paper. The definitive version is available from: http://onlinelibrary.wiley.com/doi/10.1111/hojo.12034/abstract

The lower standard of proof was ultimately defended on the basis that the PND system allows the recipient to contest the notice and elect for a trial. The government argued that the PND scheme was in no way coercive but rather is a system based on consent; the recipient either consents to receiving the notice and pays the PND or elects to go to court. The right to trial, it was stated, was in no way qualified. Notably however the achievement of the managerialist aims of the PND scheme is reliant on a low rate of contest, a fact the government recognised when setting the penalty notice fee stating that it needed to be high enough to deter offending, but not so high that recipients would elect to go to court in the hope of a lower penalty. Whilst PND recipients retain the right to a trial, in practice very few ever exercise this right. Since the system was introduced the percentage of contested cases has remained steady at $1 \%$ (Ministry of Justice 2011, Table A2.1). Whilst this supports the efficiency of the system, it seriously questions whether recipients are aware of the difference in the standard of proof applied when they are issued with a notice and that which would apply in court, or the different evidential requirements applied at each stage, and indeed, whether PND recipients view their right to contest the notice as a genuine option at all. Such concerns were recognised during the debate on the original Bill, as it was argued that receipt of a PND "has the immediate implication that they have been judged and found wanting" (Dominic Grieve (Con), Stg Co Deb (2001-2) Third Delegated Legislation Committee, $18^{\text {th }}$ June 2002, col.6). This may discourage recipients from seeking advice about their legal rights. This was thought to be particularly true of the most vulnerable recipients, thus further compounding the potential for injustice. Yet such concerns had no impact on the development of the scheme.

\section{Equality of Impact}

One of the main concerns regarding PNDs was that they could discriminate against the most vulnerable; a fixed penalty would have a differential impact according to the means of the recipient. People on low incomes, those who survive on benefits, asylum seekers and the homeless were all cited as being less likely to be able to pay a PND, and therefore have a fine 
This is a pre-publication version of this paper. The definitive version is available from: http://onlinelibrary.wiley.com/doi/10.1111/hojo.12034/abstract

registered against them (Stg Co Deb, (2000-1) Co F Criminal Justice and Police Bill, no pagination). The government rejected such concerns stating that it is a necessary consequence of a fixed penalty system that the fee is standardised, and that there was some flexibility in the system as unpaid PNDs registered as a court fine may (at the discretion of the court) be paid by instalment. However, once registered as a court fine the value of the penalty is increased by $50 \%$, therefore, those who cannot afford to pay the initial amount are further penalised for the privilege of paying by instalment. When this issue was raised, the government argued that recipients could avoid the additional fee by electing to challenge the notice in the first instance. Therefore those who cannot afford to pay their PND can either contest the notice and risk being convicted, or leave the PND unpaid and hope that the court allows them to pay the (now increased) fine by instalments. The government further argued that the police would exercise their discretion when deciding whether to issue PNDs and may use other options if people were deemed to be of limited means. However this endorses a two-tier justice system whereby those deemed to be able to afford it will be issued with a PND and, provided that it is paid in 21 days, receive no criminal record, and those who are deemed to be of limited means will be prosecuted or receive a caution.

National data on the use of PNDs provide insight into the gender and ethnic profile of PND recipients; they are mostly male (75\%) and white (86\%) (Ministry of Justice 2011, Tables Q2.2 and Q2a). However information on employment status; which may provide some indication of recipients' ability to pay is not given in the national data. The current study found that in the force area reviewed $51 \%$ of tickets were issued to people who were unemployed. Furthermore, unemployment was significantly related to failure to pay the notice ( $\mathrm{X} \square=23.893$, d.f $=2 \mathrm{p}<0.001$ ); only $31 \%$ of unemployed people paid the notice compared to $59 \%$ of people who were employed. This suggests that in practice concerns regarding inequality of impact are being realised.

\section{Discussion}


This is a pre-publication version of this paper. The definitive version is available from: http://onlinelibrary.wiley.com/doi/10.1111/hojo.12034/abstract

The above analysis highlights the aims of the PND scheme, but where do the introduction, and development of penalty notices fit within a broader policy context? In trying to contextualise PNDs within the broader crime and ASB policy, they appear to stand quite outside, and indeed contradict, the communitarian, multi-agency approach to ASB that has otherwise been propagated by both the Labour and Coalition governments (Crawford 2007, Ministry of Justice 2010). PNDs only share the common drive for managerialism; finding efficient means of dealing with offenders which would be both cost and time effective. Initiatives to tackle ASB were initially grounded in the context of social housing management (Flint 2004), and increasingly became focused on disorderly behaviour in neighbourhoods and youth disorder. Indeed, the Respect Action Plan (Home Office 2006) only discussed adult offending within the context of 'problem families' and substance misuse, making little mention of PNDs and no mention of binge drinking or drunk and disorderly behaviour.

This approach continues to be mirrored in the current government's ASB policy; their 2011 review of ASB powers remained focused on targeting neighbourhood disorder rather than the one-off acts of disorder, largely perpetrated in town and city centres, which are targeted by PNDs. PNDs also fail to reflect the 'responsibilisation' and conditionality espoused by other ASB strategies, which seek to restrict and amend offenders' behaviour (Haylett 2001). The only condition attached to a PND is financial; there is no attempt to 'remoralise' the offender. Whilst the proposed PND education scheme attempts to address this, and adapt PNDs to match the rehabilitative aims of the Breaking the Cycle Green Paper (Ministry of Justice 2010) such aims are undermined as neither the establishment of, nor attendance at, these education programmes is mandatory. Thus in adopting the decentralised approach which that Paper propounds, the PND scheme is likely to continue to focus on punishment rather than rehabilitation of offenders.

Despite their focus on alcohol-related nuisance, PNDs are similarly distinct from both the Labour and the current government's Alcohol Strategies. Whilst they recognised the impact of binge drinking on crime and ASB (and health), both gave a particular focus to the "scourge 
This is a pre-publication version of this paper. The definitive version is available from: http://onlinelibrary.wiley.com/doi/10.1111/hojo.12034/abstract

of violent crime" (Home Office 2012b, p.2) which is beyond the scope of the PND scheme. Furthermore, they emphasised the need for partnership working to tackle these issues. In trying to locate PNDs in the wider ASB and Alcohol Strategies it can be seen that whilst the behaviours they seek to address are the same, the method and approach are quite distinct. PNDs are a single-agency, police-issued punishment which do not seek to amend or restrict future behaviours other than through the crude deterrence of a financial penalty. Where PNDs $d o$ find support is in both governments' drive to cut bureaucracy and improve efficiency in the CJS.

There is an inherent conflict within the managerialist drive to provide a more time and cost efficient means of dealing with, and punishing, low-level offending as there is a necessary time and cost implication to punishing such behaviour. One that is likely to increase if the alternative (and again contradictory) strategy of educating and rehabilitating the perpetrators of such offences is taken. Whilst PNDs appear to have realised some of their managerialist goals (issuing a PND is cheaper and quicker than prosecution) the net-widening associated with the scheme and the large proportion of tickets issued in custody undermine potential savings. The achievement of reductionist aims are questionable given the relative absence of research into the impact of PNDs on re-offending and the low payment rate undermines the notion that PNDs provide a swift punishment. The experience of alcohol referral schemes suggests that PND education programmes will struggle to impact upon reoffending rates, and so any rehabilitative aims seem unlikely to be realised. Furthermore, such programmes will be resource intensive, thus undermining the scheme's overall managerialist aims.

The concerns raised in parliament had a negligible impact on the debate. The fact that PND recipients retain the right to go to trial was used to justify the introduction and extension of the PND scheme, but recipients rarely exercise this right. Concerns regarding police discretion (particularly with regards to subjective offences such as s5) were ultimately dismissed in the debates, yet in practice it appears that s5 and drunk and disorderly PNDs are often used in situations where it was the issuing officer who was the victim of the offence. That PNDs will 
This is a pre-publication version of this paper. The definitive version is available from: http://onlinelibrary.wiley.com/doi/10.1111/hojo.12034/abstract

have a differential impact according to the recipient's means is clear; this is reinforced by the present research, which found that unemployed people were significantly more likely to have their PND registered as a court fine. Whilst these concerns may not have influenced the political debate they do point to potential problems with the PND scheme which need to be assessed to gain an understanding of how PNDs are used and their impact on recipients. PNDs were a new weapon in the police armoury in the 'fight against crime', one that sought an efficient means of tackling the low-level disorder that impacts upon individuals' and communities' quality of life and confidence in the police. However are the advantages offered by PNDs sufficient to outweigh the concerns raised? Especially given that negative experiences of contact with the police also impact upon public confidence? Future research needs to address (if and) how the aims of the PND scheme can be realised whilst minimising their unequal impact and promoting the equitable use of this power and the recipient's right to a fair trial.

\section{Notes}

${ }^{i}$ Under s101 of the Criminal Justice Act 2003 receipt of a PND may be deemed evidence of bad character, however in R v Hamer [2010] EWCA Crim 2053 it was ruled that, as payment of a PND was not an admission of any offence it did not impugn good character of the recipient and as such had no effect on their entitlement to a good-character direction.

${ }^{\text {ii }}$ If after 21 days the notice has neither been paid nor a court hearing requested, in exceptional circumstances (such as where further evidence as to the offence has emerged), the recipient may be prosecuted for the original offence. In practice 'potential prosecution' was the outcome for only $4 \%$ of PNDs issued in 2010 (Ministry of Justice 2011, Table 2.4).

iii In 2010 37,119 PNDs were issued for drunk and disorderly and 32,317 for s5; this is compared to 20,581 and 22,848 cases respectively which were proceeded against in the Magistrates Court (Ministry of Justice 2011, Table 2.1; Ministry of Justice 2012).

iv The initial review was comprehensive, any mention of penalty notices were coded and included in the analysis. Following the initial analysis the coded data were repeatedly reviewed and the key themes identified and categorised. Those justifications for, and concerns about, PNDs that are presented in this paper consist of those issues that arose most frequently throughout the passage of the Bill and subsequent secondary legislation.

$\checkmark$ These categories reflect the policy aims outlined in the relevant consultation documents (Home Office 2000; Ministry of Justice 2010) rather than any explicit use of such terminology within the parliamentary debates.

vi The ticket analysis was based on a quantitative assessment of a sample of 250 penalty notice tickets issued between October and November 2010 in one police force area. Penalty notice tickets consist of six sections which include information as to the offender's details and the offence time and location. The 
This is a pre-publication version of this paper. The definitive version is available from: http://onlinelibrary.wiley.com/doi/10.1111/hojo.12034/abstract

final page is consists of an evidence section to be completed by the issuing officer. Evidence data were coded to allow comparison of the circumstances of different penalty offences.

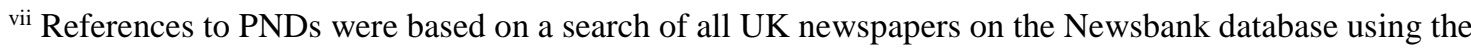
following search terms: "penalty notice for disorder" or "on the spot fine", not 'motor*', not 'driv*', not 'park*', not 'speed*'. References to ASBOs were based on a search of all UK newspapers on the Newsbank database using the following search terms: "ASBO" or "antisocial behaviour order" or "antisocial behaviour order"

viii However, the OCJR recognise that such differences may reflect the offending profile of people who receive different disposals and their propensity to re-offend and as such these results should be treated with caution.

ix Whilst the inclusion of a rehabilitative element to the PND scheme may be relatively new in legislative terms, in practice many forces operated so called waiver schemes prior to this Act. Indeed the first such scheme appears to have been established in Hertfordshire Constabulary in 2007. Now approximately half of all forces offer PND waiver schemes for alcohol-related offending, and four forces offer education programmes for people in receipt of cannabis PNDs.

${ }^{x}$ Penalty notice tickets do not have a defined section to record who the victim of the offence was. In the current study, the victim(s) were researcher-coded based on the description of the offence given in the evidence section. Victim(s) were coded in a sequential manner according to where in the evidence they appeared rather than on any subjective judgement as to the perceived importance of the victim in the event/decision to issue a penalty notice.

\section{References}

Blair, T. (2006) RESPECT Agenda Launch Speech, [Online], Available From: http://www.number10.gov.uk/Page8898 [Accessed at 13 ${ }^{\text {th }}$ October 2009]

Blakeborough, L. and Richardson, A. (2012) Summary of findings from two evaluations of Home Office alcohol arrest referral pilot schemes, Research Report No. 60, London: Home Office

Centre for Social Justice (2009) Breakthrough Britain: A Force to be Reckoned With, London: Centre for Social Justice

Choongh, S. (1998) 'Policing the Dross: A Social Disciplinary Model of Policing', British Journal of Criminology, 38, $623-634$

Crawford, A. (2007) Crime Prevention and Community Safety, In, Maguire, M., Morgan, R. and Reiner, R. (Eds.) The Oxford Handbook of Criminology, Oxford: Oxford University Press, pp. 866-909

Equality and Human Rights Commission (2010) Stop and Think: A critical review of the use of stop and search powers in England and Wales, London: Equality and Human Rights

Commission

Flint, J. (2004) 'The responsible tenant: housing governance and the politics of behaviour', Housing Studies, 19, 893-909 
This is a pre-publication version of this paper. The definitive version is available from: http://onlinelibrary.wiley.com/doi/10.1111/hojo.12034/abstract

Fox, R. (1995b) Criminal Justice on the Spot: Infringement Penalties in Victoria, Canberra: Australian Institute of Criminology

Halligan-Davis, G. and Spicer, K. (2004) Piloting 'on the spot penalties' for disorder: final results from a one-year pilot, Research Findings No. 257, London: Home Office

Haylett, C. (2001) 'Modernization, welfare and 'third way' politics: limits to theorizing in 'thirds'?' Transactions of the Institute of British Geographer's, 26, 43-56

Home Office (2012a) Penalty notices for disorder, [Online], Available From: http://www.homeoffice.gov.uk/police/penalty-notices/ [Accessed at $4^{\text {th }}$ May 2012]

Home Office (2012b) The Government's Alcohol Strategy, London: HMSO

Home Office (2006) Respect Action Plan, London: Home Office

Home Office (2000a) Reducing Public Disorder, the Role of Fixed penalty Notices: A Consultation Paper, London: Home Office

Kraina, C. and Carroll, L. (2006) Penalty Notices for Disorder Review of Practice Across Police Forces, London: Office for Criminal Justice Reform

Lee, J. A. (1981) Some Structural Aspects of Police Deviance, In, Shearing, C. (Ed.) Organisational Police Deviance. Toronto: Butterworth

Ministry of Justice (2011) Criminal Statistics: England and Wales 2010. Out of Court Disposals Tables, London: Ministry of Justice

Ministry of Justice (2010) Breaking the Cycle: Effective Punishment, Rehabilitation and Sentencing of Offenders, London: HMSO

Ministry of Justice (13 ${ }^{\text {th }}$ April 2012) PND Figures, [e-mail to: S McManus] [Online]. Available e-mail: PNDequiries@justice.gsi.gov.uk

Ministry of Justice (11 ${ }^{\text {th }}$ January 2013) PND Figures, [e-mail to: S Grace] [Online]. Available e-mail: PNDequiries@justice.gsi.gov.uk

Office for Criminal Justice Reform (2011) Initial findings from a review of the use of out-ofcourt disposals, London: Ministry of Justice

Reiner (2010) The Politics of the Police, $4^{\text {th }}$ Edition, Oxford: Oxford University Press

Silverman, D. (2010) Doing qualitative research: A practical handbook, $3^{\text {rd }}$ Edition, London: Sage 
This is a pre-publication version of this paper. The definitive version is available from: http://onlinelibrary.wiley.com/doi/10.1111/hojo.12034/abstract

Spicer, K. and Kilsby, P. (2004) Penalty Notices for Disorder: Early Results from the Pilot, London: Home Office

Young, R. (2008) Street Policing After PACE: The Drift to Summary Justice, In, Cape, E. and Young, R. (Eds) Regulating Policing: The Police and Criminal Evidence Act 1984, Past, Present and Future, Oxford: Hart Publishing 